\title{
From people to things: Building global connectivity
}

Written by: Gaël Hernandez, OECD Directorate for Science, Technology and Innovation

Last update: 8 March 2017

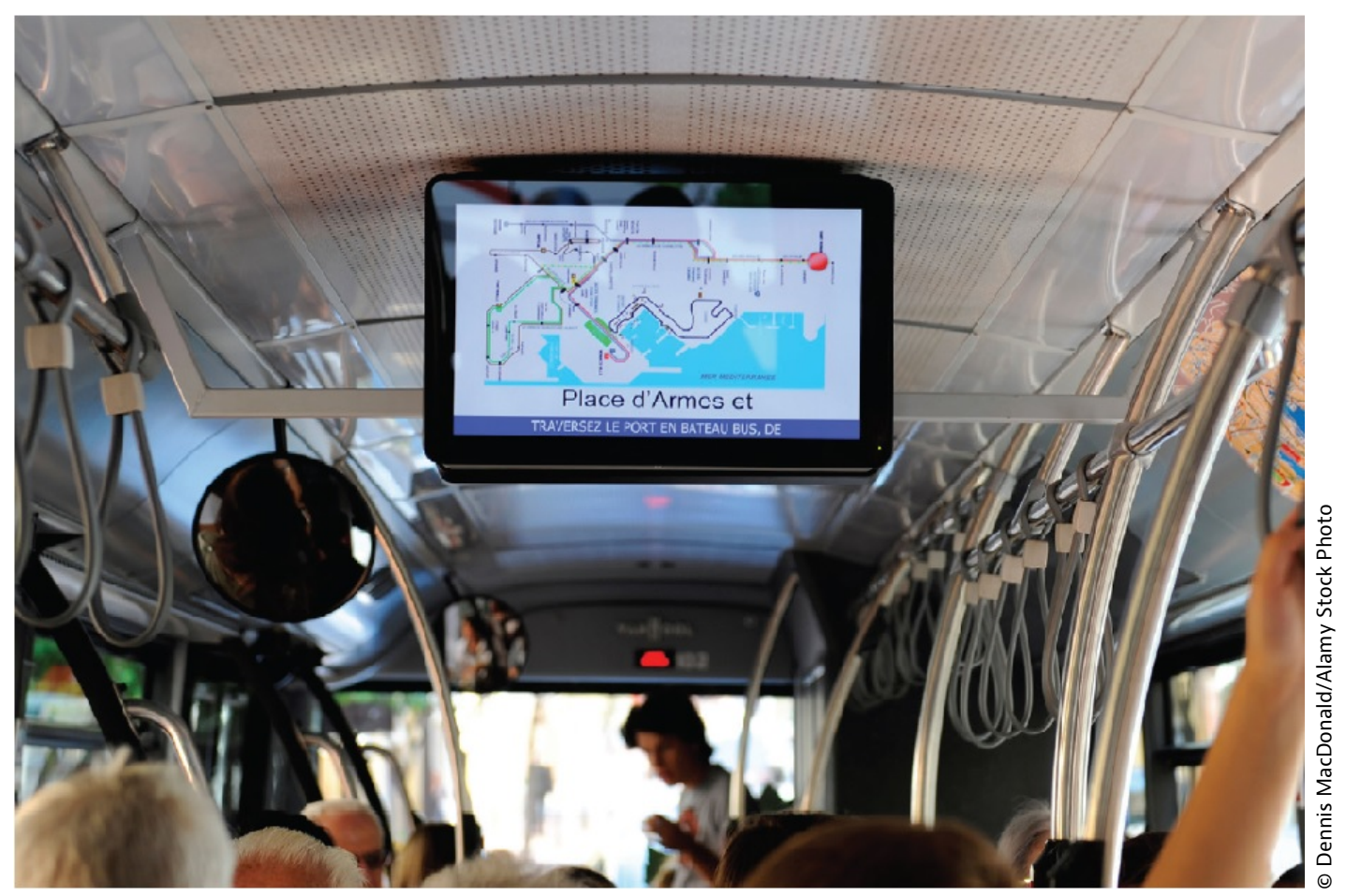

Connectivity is the foundation for the digital economy. The Internet has already connected more than three billion users across the globe and about 14 billion devices.

A major challenge is how to extend connectivity not only to the next several billion users, but also the next 50 billion devices. Thanks to the Internet of Things (IoT), the economy is digitalising on an unprecedented scale, as devices and objects connect to the Internet's network of networks and communicate with each other. A world is emerging where smart sensors and actuators will increasingly monitor the health, location and activities of people and animals, the state of the natural environment, the quality of food and more.

If connectivity is the foundation and enabler, the driver that makes all this possible is convergence. Thanks to digitalisation and the growing capabilities of the Internet, there has been an ongoing convergence between once distinct parts of the communication ecosystem. Fixed and wireless networks converge, voice 
and text, and telecommunication and broadcasting too. Your car, your home appliances: all are being connected. Companies best known for communication equipment increasingly provide content, and vice-versa. Each firm may have a competitive edge and niche function but old lines are blurring as new services and possibilities emerge all the time. Much of the time you will not be aware that the tram or stop you are waiting at are connected to the Internet, but they will have IP addresses.

The underlying communication and digital services industries, which are essential for building up global connectivity, are transforming, spurred by growth in fixed and mobile broadband penetration rates and by ever more innovation in software and smart devices.

Services such as voice, video and music are now offered not just on television and radio, but over the Internet and are increasingly integrated as content with devices or software applications, such as search. Online video distributors, such as YouTube or Netflix, offer content over broadband networks, beyond traditional cable and broadcasting services. TV broadcasters and manufacturers are also going digital and offering online packages, which can be accessed over the web. Users can choose between several devices to receive content and different price models, often at any time and any place and consumers can increasingly interact with that content. These changes have been equally profound in telecommunication with voice (VoIP) and text services such as WhatsApp, or KakaoTalk offered over the Internet, which are virtually toll free to users and competing head-on with traditional mobile texting. Both video and voice services may also be bundled on social media platforms such as Facebook and Linkedin. Meanwhile, many sectors from accommodation to transport have been disrupted as new applications enable new business services over the Internet.

But with newness and disruption come a range of challenges, as these over-thetop services undercut market positions hitherto firmly held by telecommunication, cable and broadcasting companies.

Traditionally, these different areas have been governed by different policies, regulation and involve different market participants, which raises the issue of whether current regulation is adapted to this new reality.

In addition, industry consolidation is already taking place in communications markets, with more and more mergers being approved between mobile and fixed operators, and between communication networks and content providers. Many of these mergers can help bolster network capacity and are designed to offer integrated, bundled services to meet further customer demand. However, because of their market concentration these mergers may reduce choice of provider and competition for a time, as consumers in many countries have been finding out. In short, policy makers have several dilemmas to address. How can they ensure roll out and maximum access when it comes to broadband, for instance, and not allow 
technologies, or indeed users, fall behind? How can competition, innovation and investment be assured at the same time? What role should public investment play? Is current legislation and policy fit for purpose?

\section{Internet of Things}

Answering such questions is important as we embark on the era of the Internet of Things (IoT). This not only concerns cars and home thermostats, but the likes of medical devices, even whole infrastructures. The pervasive nature of the IoT will be such that people will not always be aware of them in their home, city or workplace, but will see them as a supporting infrastructure for their way of life. The IoT is also enabling firms and public authorities to meet their objectives in new and innovative ways. In the private sector, productivity and efficiency gains will come from transforming how firms monitor their processes and outputs, equipping workers with smart devices to alert them to assembly line issues, stock changes, sudden market shifts, and more. Such devices may also help governments address important public policy goals, such as monitoring emissions and improving the environment, managing traffic or delivering public services more effectively.

The Internet of Things is happening now, with an upsurge in the development of machine-to-machine (M2M) communication modules enabling remote management applications for equipment and machines with no human intervention. OECD data since 2012 show that the number of M2M SIM subscriptions have grown from 72 to 124 million, corresponding to 10 subscriptions for each 100 inhabitants.

Together with two other developments-that of big data analytics and the advent of cloud computing with its better processing power and cost-effective tools for globally scalable applications-a new digital economy is evolving fast. It is up to policy makers to stay ahead of these trends by asking the right questions: for instance, what are the implications of an increasingly widespread deployment of IoT for communications infrastructures and services? What changes in existing policies and practices could facilitate the adoption of IoT enabled services, such as remote health monitoring? And what actions can be taken to build trust in the IoT applications and services? But whatever the question, it is important to remember that as connectivity and convergence are at the basis of the Internet, they will influence the success of the Internet of Things too.

www.oecd.org/sti 